\title{
Erratum to: Monitoring $k$ th order runs in binary processes
}

\section{Christian H. Weiß}

Published online: 13 June 2012

(C) Springer-Verlag 2012

\section{Erratum to: Comput Stat \\ DOI 10.1007/s00180-012-0316-2}

In the original publication of the article, Fig. 1 is incorrect. It shows the same graph as Fig. 2. The correct version of Fig. 1 is given below:

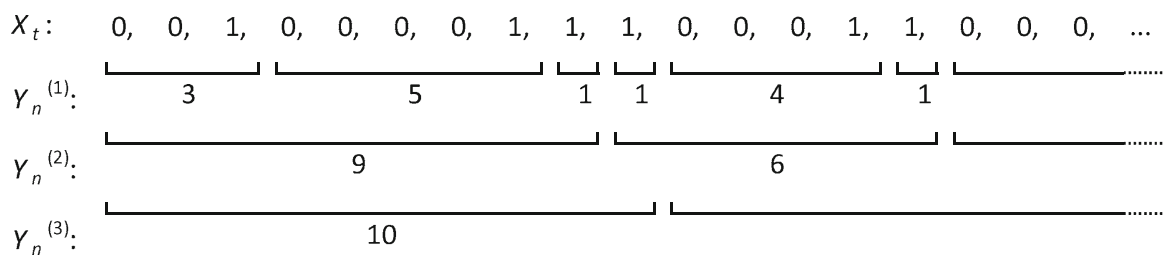

Fig. 1 1st, 2nd and 3rd order runs in a binary process $\left(X_{t}\right)_{\mathbb{N}}$

The online version of the original article can be found under doi:10.1007/s00180-012-0316-2.

C. H. Weiß $(\varangle)$

Department of Mathematics, Darmstadt University of Technology,

Schlossgartenstraße 7, 64289 Darmstadt, Germany

e-mail: weiss@mathematik.tu-darmstadt.de 